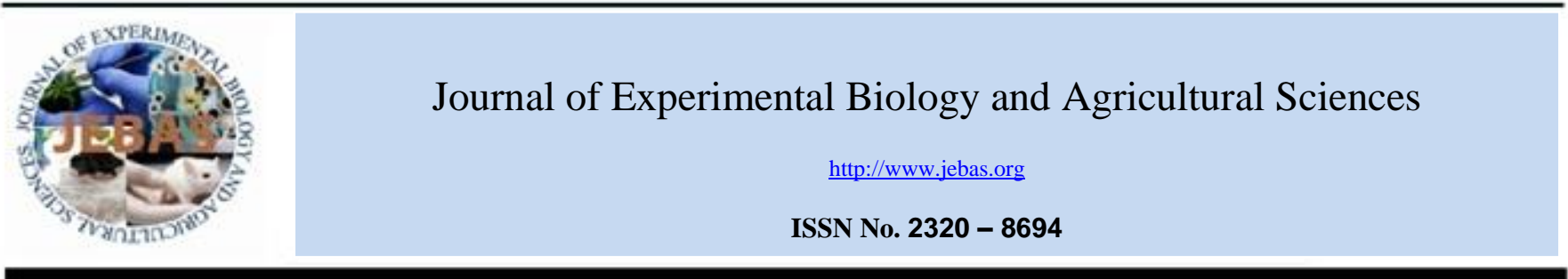

\title{
STUDY OF AZO COMPOUNDS DERIVED FROM P-CRESOL LIGAND: SYNTHESIS, CHARACTERIZATION AND BIOLOGICAL ACTIVITY
}

\author{
Hutham mahmood Yousif Al-labban ${ }^{1}$, Adil ibadi Al-luhaiby ${ }^{2}$, Nuha salman salih ${ }^{1}$, \\ Widad ibrahem Yahya ${ }^{1}$, Ahmed Abdul jabbar Jaloob Aljanaby ${ }^{3 *}$ (ic
}

${ }^{1}$ Department of Chemistry, Faculty of Science, University of Kufa, Iraq

${ }^{2}$ Department of Laboratory Investigation, Faculty of Science, University of Kufa, Iraq

${ }^{3}$ Department of Biology, Faculty of Science, University of Kufa, Iraq

Received - May 18, 2021; Revision - June 16, 2021; Accepted - June 24, 2021

Available Online - June 25, 2021

DOI: http://dx.doi.org/10.18006/2021.9(3).401.406

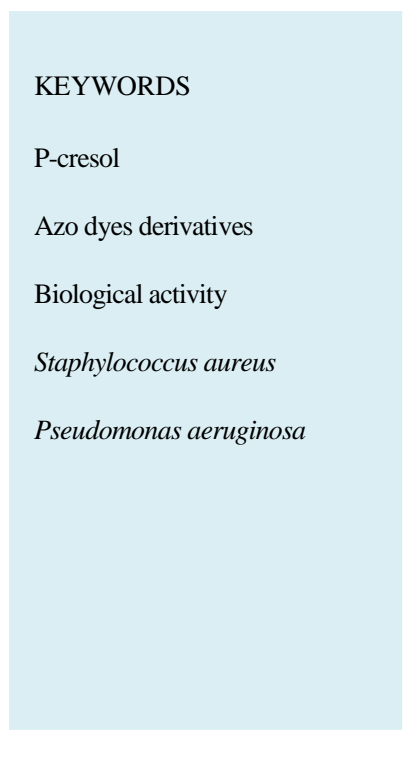

\begin{abstract}
Azo compounds contain two aromatic rings separated by an azo $(-\mathrm{N}=\mathrm{N}-)$ link. These are versatile molecules that have garnered a lot of interest in both basic and applied research. In this work, synthesis of some Azo dyes derivatives by coupling P-cresol with diazonium salts obtained from p-chloroaniline and p-methoxyaniline. The structure of the synthesized compound has been characterized by using techniques like UV-Vis Spectroscopy, and Fourier-transform infrared spectroscopy (FTIR). In addition, the antimicrobial activity of these synthesized dyes compounds was examined by using the disc diffusion method against gram negative and gram positive bacteria Staphylococcus aureus and Pseudomonas aeruginosa which have been isolated from the patients of wound infection. Further, synthesized compounds showed moderate to significant inhibitory effect at the selected concentrations against the tested microorganisms. The results of antibacterial activities demonstrated that compound pchloroaniline had good antibacterial activity against $S$. aureus and P. aeruginosa at the concentration of $300 \mathrm{mg} / \mathrm{ml}$ with $8.079 \mathrm{~mm}$ and $6.16 \mathrm{~mm}$ inhibition zone, diameter respectively. This study synthesized two new compounds viz., p-chloroaniline and p-methoxyaniline, and among these two p-chloroaniline has good anti-bacterial activity against $S$. aureus. Therefore, this can serve as a new compound for the manufacture of ointment to treat wound infections.
\end{abstract}

* Corresponding author

E-mail: ahmedaj.aljanabi@uokufa.edu.iq (Ahmed abdul jabbar Jaloob Aljanaby)

Peer review under responsibility of Journal of Experimental Biology and Agricultural Sciences.

Production and Hosting by Horizon Publisher India [HPI] (http://www.horizonpublisherindia.in/).

All rights reserved.
All the articles published by Journal of Experimental Biology and Agricultural Sciences are licensed under a Creative Commons Attribution-NonCommercial 4.0 International License Based on a work at www.jebas.org.

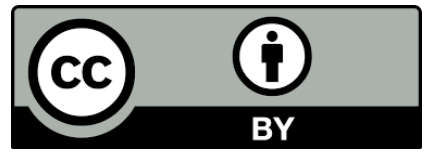




\section{Introduction}

Aromatic rings divided by an Azo $(\mathrm{N}=\mathrm{N}-)$ bonds have received considerable research attention in the fundamental and applied sciences. The high electrical absorption limit can be moved anywhere between the ultraviolet and red visible ranges by replacing the ring, allowing chemical color fine-tuning. This, along with the fact that Azo dyes are unexpectedly solid and chemically resistant, has sparked many dyes and colorant development (Sarigul et al., 2017). These dyes have been widely used in the clothing, fabric, leather, and paint sectors, biological-medical research, and advanced organic synthesis applications for more than a century due to their capacity to absorb visible light and ease of synthesis (Malinovi et al., 2017). The types of dyes that are commonly made in high-volume are thought to be rather recalcitrant. Textiles are the main consumer of these colorants (Mehta \& Patel, 2016; Al-Zinkee \& Jarad, 2019). Azo dyes are commonly synthesized; their initial primary aromatic amine has been attached to an activated carboxylamine, so it would be coupled with nucleophiles to form a dye (Kyei et al., 2020). Azo compounds are considered the most basic industrial dyes and are employed as coloring agents and pigments (Feng et al., 2012; Shama et al., 2014; Ekennia et al., 2015; Fu et al., 2017). Azo dyes are also well-known for their antibacterial, antifungal neoplastic, anticancer, anti-inflammatory, and other pharmacological (Alkazily \& Alasedi, 2013; Kassa, 2015). A recent study explained the synthesis and characterization of 2[(4-Subithenhydrazinyl)phenol) hydrazide] (HL), a phenolic function group with a phenol substituent. A photophysical study of the chemical and electronic composition has been done, as well as through spectroscopy. The aim of this study is the synthesis of new derivatives compounds from p-cresol ligand and characterization of the synthesized compounds along with biological activity against two aerobic pathogenic gram-positive ( $S$. aureus) and gram-negative ( $P$. aeruginosa) bacteria isolated from the patients suffering from wound infection.

\section{Materials and Methods}

\subsection{Chemicals}

The purest grade chemicals have been used in its preparation of azoic Azo dyes (Merck Company, Germany) uses only the purest form of azoic dyes in the formulation of Azo pigments unconducting is done by using Stuart model 9300 melting point process by means, which included the analysis of elemental $\mathrm{C}, \mathrm{H}$, and $\mathrm{N}$ using a C.H.N.S (Carbon Hydrogen and Nitrogen analyzer device, Germany). EA-3000 multi-mm tool. The $\mathrm{KBr}$ samples showed strong infrared absorption bands in the range of $400 \mathrm{~cm}^{-1}$ to $7,000 \mathrm{~cm}^{-1}$ on the Shimadzu spectrophotometer (not an IR line). These techniques were used to obtain an electronic spectrum on a Shimadzu 1700 UV spectrophotometer with flame ionization via a
Shimadzu GC2014 with a flame detection element that used to detect substance (Kyei et al., 2020).

\subsection{Synthesis of Azo ligand}

Preparation of Azo bisubstirenone before adding the 4-substit phenol Azo connection extracts prepared from glycerol was used as substrates to produce p-chlorbenzene diamine ligands. According to the literature, a solution of $302 \mathrm{~g}$ of p-chloricotrityl chloride and $289 \mathrm{~g}$ of pindanedion is combined with $25 \mathrm{ml}$ of concentration (Adam et al., 2019). $\mathrm{HCl}$ then $2.876 \mathrm{~g}$ of piperazine, was stirred, and the mixture was applied to a solution of $25 \mathrm{~g}$ of $\mathrm{Na}_{2} \mathrm{O}$ which dissolved in $100 \mathrm{ml}$ of water at room temperature with constant stirring and undercooling (this was followed by the mixing of $4.18 \mathrm{ml}$ of $\mathrm{p}$-cresol with $0.3 \mathrm{~g}$ of $\mathrm{NaOH}$ and cooled to keep the solution until it clear). $\mathrm{PHCl}$ was diluted with water until the mixture had a $\mathrm{pH}$ of 8 this was followed by filtration and recrystallized twice with the hot ethanol, and allowed to dry for many hours, and then washed and purified with water (Al-Labban, 2017). Figure 1 and Table 1 listed the properties and FTIR spectra of the compounds.

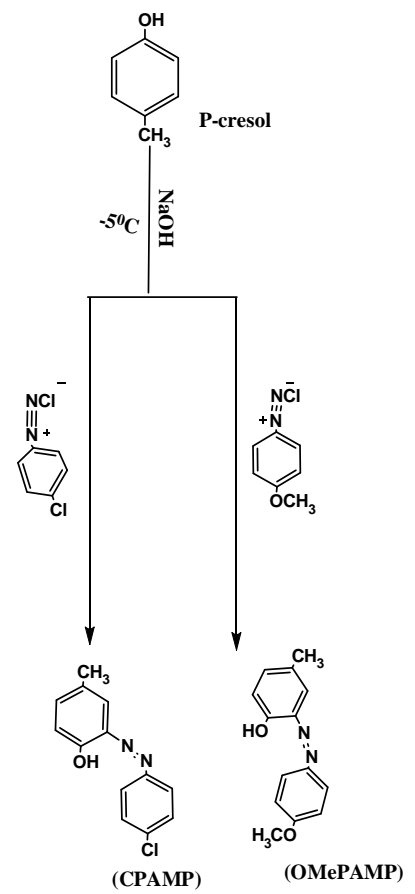

Figure1 Synthesis of Azo ligand

\subsection{Examination of biological activity}

Two derivatives compounds have been examined to inhibit two kinds of pathogenic bacteria (gram-positive S. aureus and gramnegative $P$. aeruginosa) isolated from the patients suffering from wound infection. Collection and maintenance of the selected bacterial pathogens were carried out by the Microbiology 
Laboratory, Faculty of Science, University of Kufa. The antibacterial properties of the synthesized Azo dye were measured using the agar well diffusion method (Aljanaby \& Aljanaby, 2018; Al-labban \& Aljanaby, 2020). For this, selected pathogenic bacteria were swabbed on the Muller-Hinton agar surface as per the 0.5 McFarland turbidity (Aljanaby, 2013; Aljanaby, 2018, Hayder \& Aljanaby, 2019). Each derivative compound was made in three concentrations viz., 100, 200, and $300 \mathrm{mg} / \mathrm{ml}$. Crockpoorer was used to make three wells in Muller-Hinton agar surface. Every well-received $50 \mu 1$ of each dilution, which was left at $20^{\circ} \mathrm{C}$ for two hours before being incubated at $37^{\circ} \mathrm{C}$ for 24 hours. Each concentration was repeated three times. The inhibition zone for every well's was calculated in millimeters (Majeed \& Aljanaby, 2019).
UV-VIS and IR spectra were used to identify these molecules as represented in Figures 2 and 3.

\subsection{Biological activity}

The result of the study revealed that $300 \mathrm{mg} / \mathrm{ml}$ concentration of $\mathrm{p}$ chloroaniline molecule had strong anti-bacterial activity against gram-positive bacteria $S$. aureus and gram-negative $P$. aeruginosa (Figure 4), with inhibition zones of $8.079 \mathrm{~mm}$ and $6.164 \mathrm{~mm}$, respectively (Table 2). This concentration is significantly different than the rest two concentrations. Furthermore, used concentrations $100 \mathrm{mg} / \mathrm{ml}$ and $200 \mathrm{mg} / \mathrm{ml}$ are not significantly different from each other.

Table 1 demonstrates the fundamental scientific findings as well as physical features of organic compounds

\begin{tabular}{|c|c|c|c|c|c|c|}
\hline Compound & M. Wt. & Yield (\%) & M.P $\left({ }^{\circ} \mathrm{C}\right)$ & Color & $\mathrm{Rf}$ & Found (calc.) $\%$ \\
\hline & & & & & & \\
\hline CPAMP & 246.06 & 70 & 154 & Yellow & 0.82 & $\begin{array}{lll}63.29 & 4.49 & 11.36 \\
64.06 & 4.29 & 11.64\end{array}$ \\
\hline OMePAMP & 242.27 & 80 & 95 & Red brown & 0.85 & 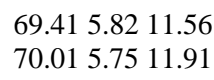 \\
\hline
\end{tabular}

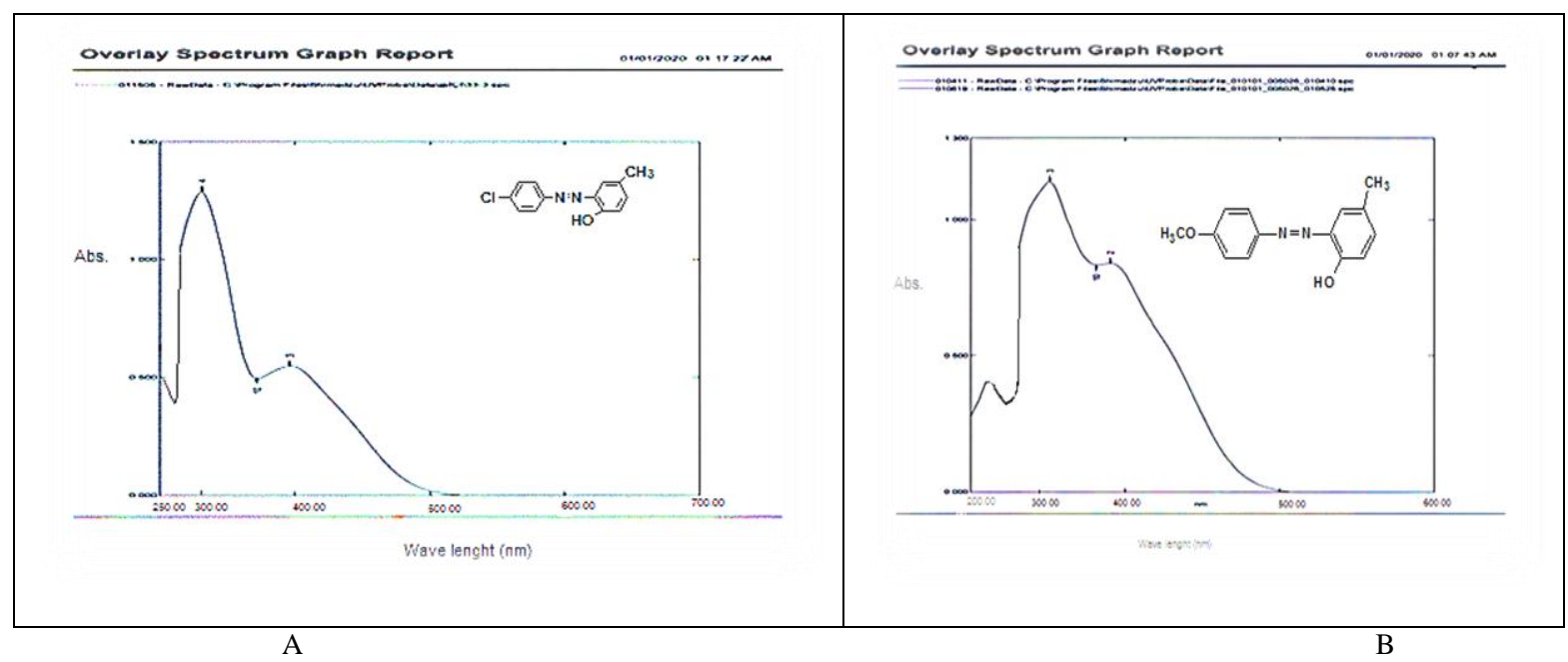

Figure 2 Organic reagents in ethanol solvent have a UV-Vis spectrum (A: p-chloroaniline, B: p-methoxyaniline)

\subsection{Statistical Analysis}

T-test comparisons between inhibition zone diameters are made using Graph-pad prism V.5 windows tools in statistical analysis (Al-Labban, 2017; Mohammed \& Aljanaby, 2020).

\section{Results}

The first step of this research involves the development of two Azo ligands that are P-cresol derivatives.

\section{Discussions}

Results presented in Figure 2 and Figure 3 revealed the final configurations of the synthesized ligands by $\mathrm{C}, \mathrm{H}$, and $\mathrm{N}$ using a C.H.N.S (Carbon Hydrogen and Nitrogen analyzer device, Germany), and the properties of the synthesized compounds are represented in Table 1 by finding a match between the theoretical measurement and experimental estimates (Al-Labban, 2017). In the case of anti-bacterial properties, the derivative compound pchloroaniline $(300 \mathrm{mg} / \mathrm{ml})$ has the highest activity against $S$.aureus

Journal of Experimental Biology and Agricultural Sciences http://www.jebas.org 
(Table 2; Figure 3). Azo compounds are very important organic materials that have attracted much attention in both applied and basic research (Abdallah, 2012; Kyei et al., 2020). They are an important class of molecules used in many requirements such as pigments, indicators, textiles, dyes, food additives, pharmaceuticals, cosmetics, therapeutic agents, and antibacterial (Jarad et al., 2018). These compounds containing bis-1,3,4-thiadiazole ring derived from nicotinic and isonicotinic acids have been synthesized via diazotization, etherification and cyclization have antimicrobials activity against many gram-positive and gram negative bacteria (Tomi et al., 2014).

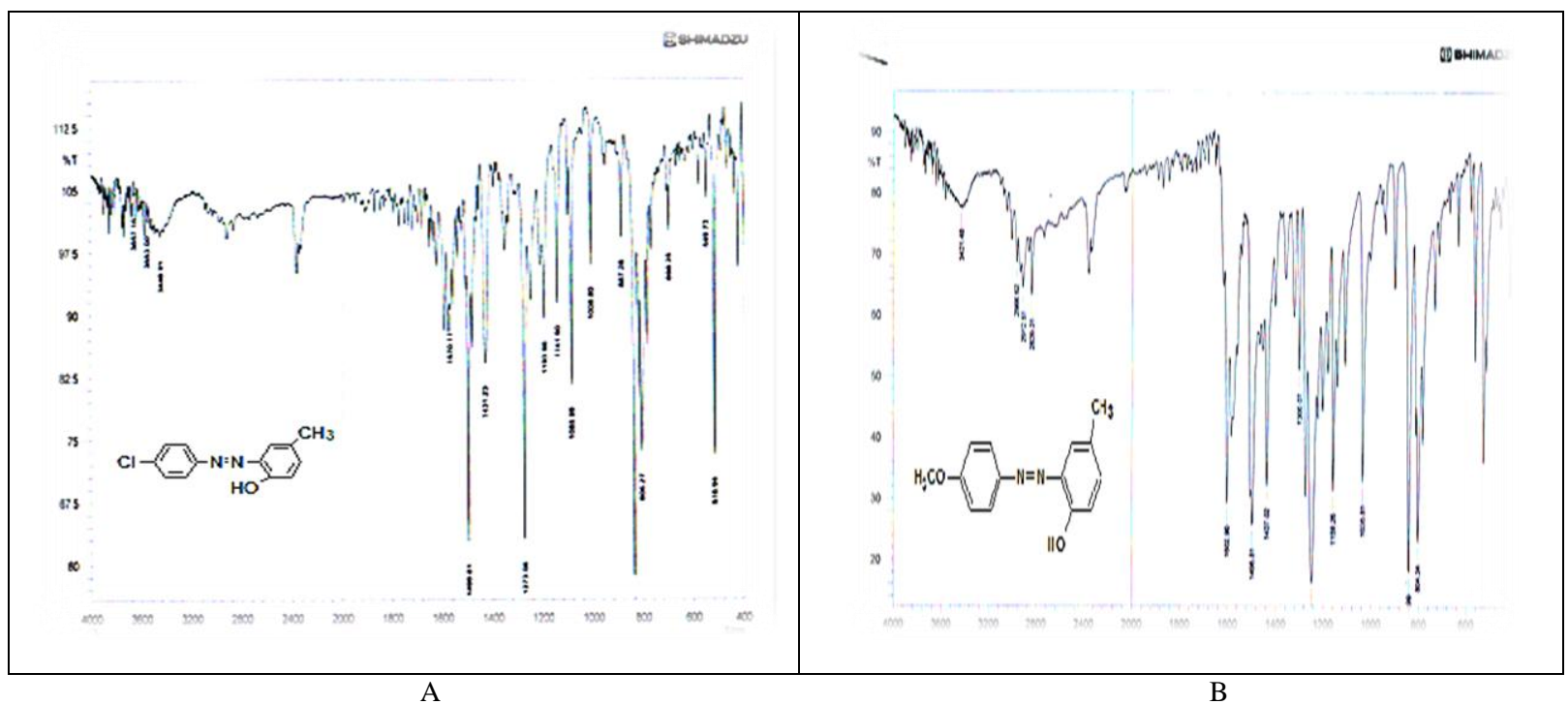

Figure 3 FTIR spectra for organic reagents (A: p-chloroaniline, B: p-methoxyaniline)

Table 2 Effect of two derivative compounds' against two multidrug-resistant pathogenic bacteria

\begin{tabular}{|c|c|c|c|c|}
\hline \multirow{3}{*}{ Derivative compound } & \multicolumn{4}{|c|}{ Multi-drug resistance pathogenic bacteria } \\
\hline & \multicolumn{2}{|c|}{ Gram positive $S$. aureus } & \multicolumn{2}{|c|}{ Gram negative $P$. aeruginosa } \\
\hline & Concentration $(\mathrm{mg} / \mathrm{ml})$ & $\mathrm{M} \pm \mathrm{SE} \mathrm{mm}(\mathrm{R}=3)$ & Concentration $(\mathrm{mg} / \mathrm{ml})$ & $\mathrm{M} \pm \mathrm{SE} \operatorname{mm}(\mathrm{R}=3)$ \\
\hline \multirow{3}{*}{ p-chloroaniline } & 100 & $5.880 \pm 0.2782$ & 100 & $3.954 \pm 0.1629$ \\
\hline & 200 & $6.896 \pm 0.3465$ & 200 & $4.605 \pm 0.3052$ \\
\hline & 300 & $8.079 \pm 0.0700$ & 300 & $6.164 \pm 0.2770$ \\
\hline \multirow{3}{*}{ p-methoxyaniline } & 100 & $3.2610 \pm 0.1591$ & 100 & $3.947 \pm 0.04914$ \\
\hline & 200 & $3.3530 \pm 0.2494$ & 200 & $3.967 \pm 0.1532$ \\
\hline & 300 & $3.750 \pm 0.3821$ & 300 & $5.586 \pm 0.2050$ \\
\hline
\end{tabular}

$\mathrm{M} \pm \mathrm{SE}$ : Mean \pm Standard error, mm: Millimeter (diameters of inhibition zone), R: number of replicates

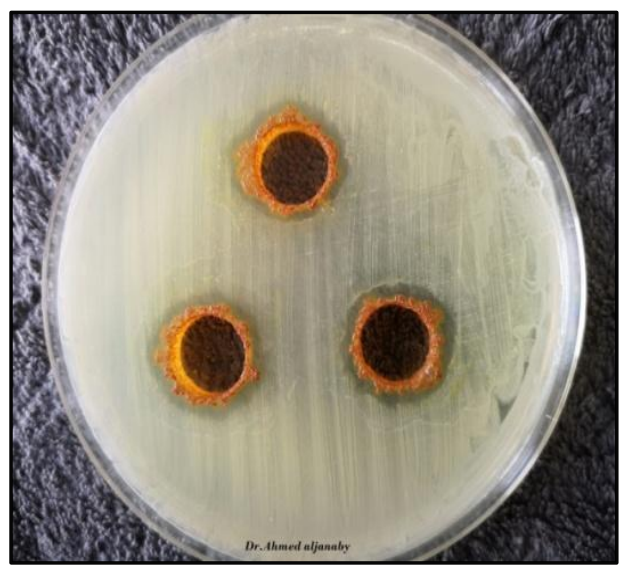

Figure 4 Antibacterial activity test of derivative compound p-chloroaniline $(300 \mathrm{mg} / \mathrm{ml})$ against S.aureus

Journal of Experimental Biology and Agricultural Sciences http://www.jebas.org 


\section{Conclusions}

In this study, two new derivatives compounds p-chloroaniline and p-methoxyaniline have been synthesized from the p-cresol ligand and among these synthesized compounds p-chloroaniline exhibited significant antibacterial activity against two pathogenic bacteria $S$. aureus and $P$. aeruginosa isolated from wound infection patients. In this manner, p-chloroaniline can serve as a raw material for the development of new drugs in the treatment of wound infection.

\section{Conflict of Interest}

This study does not have any conflict of interest.

\section{Funding}

There was no fund issued by any organization for this study, fund arranges by authors themselves.

\section{References}

Abdallah SM (2012) Metal complexes of azo compounds derived from 4-acetamidophenol and substituted aniline. Arabian Journal of Chemistry 5(2):251-256.

Adam RW, Al-Labban HM, Aljanaby AAJ, Abbas NA (2019) Synthesis, characterization and antibacterial activity of some new of novel 1, 2, 3-Triazol-Chalcone derivatives from N-Acetyl-5HDibenzo [b, f] Azepine-5-Carboxamide. Nano Biomedicine and Engineering 11(2):99-110.

Aljanaby AAJ (2013) Antibacterial activity of an aqueous extract of Petroselinumcrispum leaves against pathogenic bacteria isolated from patients with burns infections in Al-najaf Governorate, Iraq Research on Chemical Intermediates 39(8):3709-14.

Aljanaby AAJ (2018) Antibacterial activity of an aqueous extracts of Alkannatinctoria roots against drug resistant aerobic pathogenic bacteria isolated from patients with burns infections. Russian Open Medical Journal 7(1):1-6.

Aljanaby AAJ, Aljanaby IA (2018) Prevalence of aerobic pathogenic bacteria isolated from patients with burn infection and their antimicrobial susceptibility patterns in Al-Najaf City, Iraq-a three-year cross-sectional study. F1000Research 7(1157):1157.

Alkazily WI, Alasedi KK (2013) Analysis of P-cresol Derivatives by Gas Chromatography. Journal of Analytical Techniques 3(1):19.

Al-Labban HM (2017) Synthesis, characterization and study of biological activity of some new 1, 2, 3, 4-Tetrazole derivatives. Research Journal of Pharmacy and Technology 10(10):3645-52.
Al-labban HM, Aljanaby AAJ (2020) An overview of some heterocyclic organic compounds; synthesis, characterization, thermal properties and antibacterial activity. International Journal of Pharmaceutical Research 1: 2394- 2399.

Al-Zinkee JM, Jarad AJ (2019) Synthesis, spectral studies and microbial evaluation of azo dye ligand complexes with some transition metals. Journal of Pharmaceutical Sciences and Research 11(1): 98-103.

Ekennia AC, Onwudiwe DC, Ume C, Ebenso EE (2015) Mixed ligand complexes of $\mathrm{N}$-methyl-N-phenyl dithiocarbamate: synthesis, characterisation, antifungal activity, and solvent extraction studies of the ligand. Bioinorganic chemistry and Applications 12:913424.

Feng J, Kweon O, Xu H, Cerniglia CE, Chen H (2012) Probing the NADH-and methyl red-binding site of a FMN-dependent azoreductase (AzoA) from Enterococcus faecalis. Biochemistry and Biophysics 520(2):99-107.

Fu X, Wei Z, Xia C, Shen C, Xu J, Yang Y, Wang K, Zhang P (2017) Palladium-Catalyzed Direct Ortho $\mathrm{C}-\mathrm{O}$ bond construction of Azobenzenes with Iodobenzenediacetate via $\mathrm{C}-\mathrm{H}$ Activation.Catalysis Letters 147(2):400-6.

Hayder T, Aljanaby AAJ (2019) Antibiotics susceptibility patterns of Citrobacterfreundii isolated from pa-tients with urinary tract infection in Al-Najaf governorate-Iraq. International Journal of Research in Pharmaceutical Sciences 10(2):1481-1488.

Jarad AJ, Majeed IY, Hussein AO (2018) Synthesis and spectral studies of heterocyclic azo dye complexes with some transition metals. Journal of Physics: Conference Series 1003: (1): 012021.

Kassa A (2015) Synthesis, Characterization AND Antimicrobial Activities OF $\mathrm{Ni}$ (II)-AND $\mathrm{Cu}$ (II)-Complexes $\mathrm{OF} \quad \mathrm{N}$ Pyrazolylpropanamide. Palgo Journal of Medicine and Medical Sciences 2(1):24-32.

Kyei SK, Akaranta O, Darko G (2020) Synthesis, characterization and antimicrobial activity of peanut skin extract-azo-compounds. Scientific African 8:e00406.

Majeed HT, Aljanaby AAJ (2019) Antibiotic susceptibility patterns and prevalence of some extended spectrum betalactamases genes in gram-negative bacteria isolated from patients infected with urinary tract infections in Al-Najaf City, Iraq. Avicenna Journal of Medical Biotechnology 11(2):192.

Malinović BN, Pavlović MG, Djuričić T (2017) Electrocoagulation of textile wastewater containing a mixture of organic dyes by iron 
electrode. Journal of Electrochemical Science and Engineering 7(2):103-110.

Mehta KK, Patel AD (2016) Synthesis, characterization, biological and chelating properties of new antipyrine derived azo dyes and its transition metal complexes. ActaChimica and Pharmaceutica Indica 6:26-31.

Mohammed EH, Aljanaby AAJ (2020) Galectin3 and cd16 play an important immunological role in patients infected with salmonella typhi. International Journal of Research in Pharmaceutical Sciences 11(3): 4162-4169.

Sarigul M, Kariper SE, Deveci P, Atabey H, Karakas D, Kurtoglu
M (2017) Multi-properties of a new azo-Schiff base and its binuclear copper (II) chelate: Preparation, spectral characterization, electrochemical, potentiometric and modeling studies. Journal of Molecular Structure 1149:520-9.

Sharma AA, Kasem M, Ali E, Moustafa ME (2014) Synthesis and characterization of some new azo compounds based on 2, 4dihydroxy benzoic acid. Journal of Basic and Environmental Sciences 1:76-85.

Tomi IH, Al-Daraji AH, Al-Qaysi RR, Hasson MM, Al-Dulaimy KH (2014) Synthesis, characterization and biological activities of some azo derivatives of aminothiadiazole derived from nicotinic and isonicotinic acids. Arabian Journal of Chemistry 7(5):687-94. 